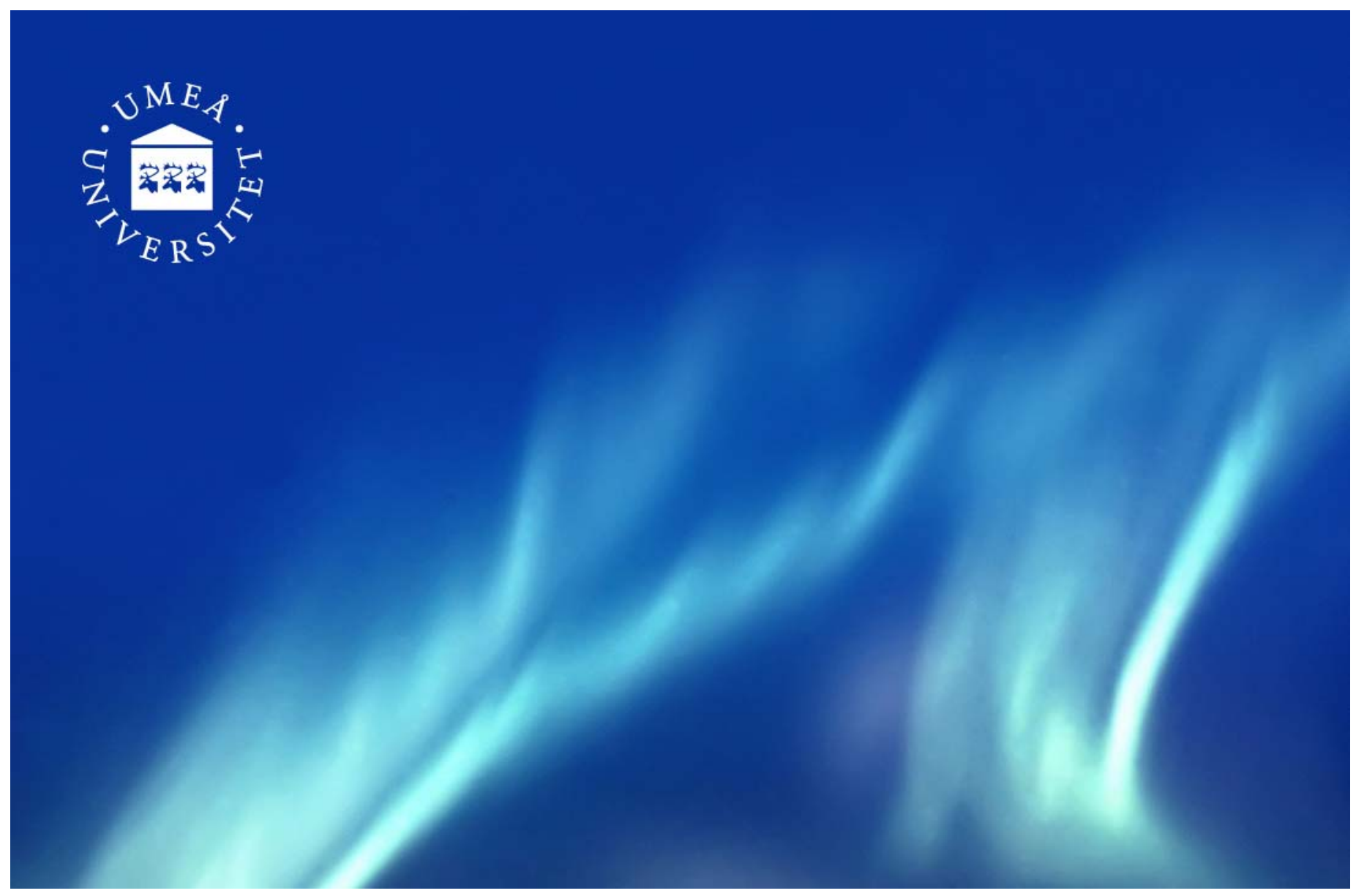

DiVA - Digitala Vetenskapliga Arkivet http://umu.diva-portal.org

This is a paper presented at International Conference on Information Communication Technologies in Education (ICICTE), Rhodes, Greece, 5-7 July 2012.

Citation for the published paper:

Tor Söderström, Jan Åström, Greg Anderson

A Framework for the Design of Computer Assisted Simulation Training for Complex Police Situations

Proceedings of Research in Educational Technology: Development and Practice. The International Conference of Information Communication Technologies in Education, 2012, p. 146-154 


\title{
A Framework for the Design of Computer-Assisted Simulation Training for Complex Police Situations
}

\author{
Tor Söderström and Jan Åström \\ Umeå University, Sweden
}

\author{
Greg Anderson \\ Justice Institute of British Columbia, Canada
}

\begin{abstract}
The article reports progress concerning the design of a computer-assisted simulation training (CAST) platform for developing decision-making skills in police students. The overarching aim is to outline a theoretical framework for the design of computer-assisted simulation training to facilitate police students' development of search techniques in complex interactions within the built environment, learning to apply and perform the five "quick peek" techniques for information gathering and subsequent risk evaluation. The article draws on Luckin's $(2010,2008)$ ecology of resources model of learner context informed with perspectives on reflective thinking from Schön (1983, 1987). The article discusses design issues within the ecology of resources model applied on CAST for complex police situations.
\end{abstract}

\section{Introduction}

To practice in order to learn how to manage complex situations is an important part of the training of police students. To manage complex situations both specific practical techniques for a situation and the thinking that guides the action need to be trained. In most cases the training is conducted through different practical exercises (e.g., drill exercises, scenario training); however, this practical training generally demands large resources investments of both time and money. Computer-assisted simulation training (CAST) provides a training platform that may offer a viable alternative for skill development in a cost effective way. How CAST is applied in educational settings and to what extent varies between the different educational areas and disciplines. For example, within the medical area the use of CAST is spreading as a viable option for training the skills necessary for professional competence (Issenberg, McGaghie, Petrusa, Lee, \& Scalese, 2005; Nehring, 2009). However, in order to use CAST to develop skills it has to be designed in a way that facilitates the intended educational purpose. In general, the development and design of computer-assisted simulation training for educational purposes requires a structured, planned and reflexive approach to enable learning (Goodyear, 2005). Although the simulation (e.g., tool) itself is important, as informed design revisions and additions can change a simulation's impact on the learning process (Chang, Chen, Lin, \& Sung, 2008; Windschitl \& Andre, 1998), the contextual aspects also affect the design process. For example, Mawdesley, Long, Al-Jibouri, and Scott (2011) added peer student exercises 
in simulation training and concluded that the support of a peer group was positively related to the students' involvement in the tasks and their evaluation of their own performance (see also Häll, Söderström, Ahlqvist, \& Nilsson, 2011). CAST, with the aim to improve knowledge and skills, is affected by contextual and educational conditions that influence how the simulation is used, and consequently its impact on learning.

This paper presents progress towards the design of computer-assisted simulation training (CAST) to facilitate police students' learning of the basic methods of local entry clearance searches - searching through areas while applying base-tactics used by the Swedish National Police Services. The overarching aim is to outline a theoretical framework for the design of computer-assisted simulation training to develop competence in complex training scenarios. Design choices to enable the learning of national standards for basic tactics using CAST are described. The theoretical framework that informs the design process draws on Luckin's ecology of resources model of learner context (Luckin, 2008, 2010), and is informed with perspectives on reflective thinking. A theoretical framework informing the design process is introduced and applied, describing the different resources in the learners' context that inform the design process. Finally, various issues concerning the CAST and its future implementation in police education are discussed.

\section{Theoretical Framework}

From a general point of view educational design is about arranging the learners' contexts to support learning of the task presented. Dewey (1910) claimed that if the subject matter is not arranged in meaningful way "the effect upon habits of thought is detrimental" (p. 188). The educational design process, in Dewey's point of view, has to consider issues that support an interest for what is to be done and incentive for doing it. This concerns a focus on the arrangement of the learner's context. It has to be relevant in relation to the students' experiences and offer a meaningful problem in order to engage the students in the process of reflection. To achieve a structural attempt in the design process, Luckin's ecology of resources model (Luckin, 2010; 2008) was applied, informed with perspectives on reflective thinking (Dewey, 1910; Schön, 1983; 1987) to form the guiding framework. For Luckin, the arrangement of the learners' context is about considering various resources and the learners' interactions with these resources. The model directs attention to the knowledge and skills resource, the tools and people resource and the environment resource with which the learner interacts. By taking into account these resources attention to adjustments and corrections intend to support an active interaction with the various resources in a specific learning situation are in focus. The emphasis on the learner's interaction with the resources and contextual adjustments and corrections surrounding the interaction (e.g., scaffolding) enables students to act on a higher level and improve understanding and knowledge (Vygotsky, 1978). Luckin emphasizes that the learner's interaction with the resources is not a direct experience - it is filtered by aspects related to the educational situation such as the task, the teachers' underlying pedagogy, or the use of technologies and their usability. Filters associated with the learners' interaction also enable and restrict the support a tool has for a learners' reflective thinking. In order to understand the 
relation between the features of the tool and the support of the thinking which guides the performance of the tactical approach, the model is informed by perspectives on reflective thinking. Using Donald Schön's $(1983,1987)$ concepts, the CAST must create room for students' reflection-in-action to support thinking on their actions, but also for reflection-on-action to support thinking upon their past performances. Schön (1983) claims that feelings of uncertainty, uniqueness, and value conflict in a situation can provide an opportunity for learners to expand their understanding of a specific issue through reflection. Reflection creates a situation that requires one to go beyond knowing-in-action which is tacit and used as long as the situation falls within the boundaries of what we have learned to treat it as normal (Schön, 1987, p. 28). Since every situation is unique searching using the local entry clearance method is a complex situation with no pre-determined correct approach. In this situation the knowing-in-action is always under pressure. When one's knowing-in-action cannot handle a situation, Schön suggests that one may respond by reflection-in-action. Reflection-in-action has a connection to present action and is about thinking what we are doing while doing it (Schön, 1983, 1987), i.e., thinking critically about events that led to the situation where knowing-in-action could not be applied. This creates on-thespot experimentation - a response that individuals take when action cannot be based on their professional repertoire of techniques, knowledge, and understanding. In this situation, people try out new actions in relation to practice. This reflective process is in an educational setting supported by various resources in Luckin's model. Schön emphasizes the importance of coaching and mentoring support for students so that they are given the opportunity to discover new dimensions of action (Schön, 1987). These indicate the importance of a design process for CAST starting from the learner's potential development with learners supported by more knowledgeable peers and teachers, or supported by CAST (more able partner (MAP), Luckin, 2010).

\section{The Design Process - Resource Considerations}

\section{Knowledge and Skills Resource: Basic Training Police Tactics}

Strategies for peaceful resolution of conflict during local entry clearance searches provide the basic premise for police tactics and conflict resolution. During basic police training the non-confrontational strategy for local entry clearance searches endorses three fundamental tactical approaches (Swedish National Police Services basic tactical instruction material):

a) Tactical risk and threat assessment (identifying risks and problem areas such as risk areas from which a possible attack can occur),

b) Control of the situation (concerning time and ability to adequately react during an active threat), and

c) The thought process (creating time for oneself, i.e., preparing, locating the perpetrator); defining the situation (e.g., can the perpetrator locate me, prepare himself, can he start an attack at me?) and finally acting.

This means that in the search police officers have to, if risk area/areas are detected from a position they control, ask themselves will they have control 
over the subsequent area during the search? This requires time and capacity for adequate response against an attack from one of the risk areas. If the answer is "yes", then the search can continue to the next area of control, but if the answer is "no", then strategies for how to search as safely as possible must be taken into consideration. The police who search the risk areas must learn to act in a way that minimizes the possibility of a successful attack by a perpetrator. One way to perform the search is to reduce the time where full control is not achieved by quickly moving forward or "peeking" into the risk areas while maintaining a position of control from which the information can be processed safely.

The aim of training for students in local entry clearance searches is to develop skilled search tactics that utilize basic principles: first, to ensure a secure retreat path is present, meaning that a risk area that is not scanned should not be passed; second, to ensure defensive tactics, and avoid, if possible, direct confrontation without having control of the existing risk area; and finally, to control the stress by dealing with as few problems and risk areas at a time as possible. During basic training the knowledge and skills the students learn include the five ways to perform a "quick peek" to receive information for judging risks which guide their actions. This search should be performed in silence. The inspection of facilities should be made by the five peeks the students learn to perform: a 3 meter peek, a 1 meter peek, centre peek, own corner peek, and cross corner peek. The 3 meter peek is done to assure that a person can move forward and perform the other peeks. The 1 meter peak is used to obtain a more reliable view of the area to be searched. The center peek is used to give a broad perception of the room. The two corner peeks (own corner peek and opposite corner peek) reveal potential threats and potential points of cover. These peeks and search should be performed with tempo change to minimize the time a person is in the risk zone.

The consequence for CAST is that the scenario developed must include the various tactics and enable training in their use. Further, legislation connected to police practice as well as the police basic tactical approach needs to be considered in the design process. If the search is performed according to the approach, the students must have the opportunity to succeed in their actions. The basic tactical approach ultimately controls the whole scenario. Three questions related to the design of the scenario must be addressed in order to make it relevant (see Dieckmann, 2009 for the importance of relevance instead of realism). The questions that initially informed the creation of the scenario were:

a) Which environment? Search an apartment/residential, warehouse/public building, office that is indoors.

b) What are the possible scenarios and ensuing actions to be performed? What should be scanned? What type of character are we dealing with (e.g., confused people, unarmed perpetrators, armed perpetrators)? What are the possible actions (up to and including lethal use of force).

c) Should all possible hiding spaces be searched? 


\section{The Computer Simulation Resource (Tool)}

The tool, in this case the computer simulation, was designed to facilitate learning the knowledge and skills that are involved in the basic tactical approach for a local entry search. Although the actual technology used or financial resources required are important, they are outside of the scope of this paper.

The tool developed in the present project used the game engine "Unreal" which provides a 3-D first person game user-interface. To accomplish the desired learning experience, the tool used scaffolding to support the negotiation of a zone of proximal adjustment (ZPA) for the learner (Luckin, 2010) and to prepare students for facing unique and complex situations where "the case is not in the book" (Schön, 1987, p. 5). This means that feedback on their actions is essential and the CAST developers are required to make decisions pertaining to the type of response to be provided for each action, and how each response may enhance reflective thinking. For example, Dewey (1910) suggests that when one is doing something, they are forced to use eyes, ears and sense of touch as guides for action which, as much as possible, has to be addressed in the design process. Researchers have suggested that the simulator's ability to give feedback provides individualized perceptual and cognitive support for the student's learning of a new skill (Nilsson, 2007; Rieber, Tzeng, \& Tribble, 2004; Silén, Wirell, Kvist, Nylander, \& Smedby, 2008). CAST, working as a scaffolding resource, provides a more able partner in Luckin's terms, and provided for improvisation, discovery and testing (Schön, 1983, 1987). Previous research found that learners need the opportunity to ruminate, evaluate, reformulate, compare, and integrate the material to be learned during the CAST to create reflections on the their experiences (Dalgarno \& Lee, 2010; de Freitas \& Oliver, 2006; Holzinger, Kickmeier-Rust, Wassertheurer, \& Hessinger, 2009; Rieber et al., 2004). Overall, the computer simulation has to provide responses to actions taken by the user to accomplish reflection-in-action while providing feedback based on the training provided to the user. The CAST is required to provide feedback that supports users' reflections on risks and risk evaluation for users who are performing a local entry search and an after-action debriefing on what they did during the search (from the perspective on medical simulations the feedback has to address the type of knowledge, skill, attitudes, or behaviour addressed in simulation (Gaba, 2004), or in Issenberg et al.'s (2005) defined outcomes or benchmarks).

The issues that informed the design of the actions the simulator was to include were:

a) The police officers conducting search should have great freedom of movement (3 dimensional), being able to move in any direction.

b) The police should be exposed to different types of attacks. Possible attacks and the scope of them should be tied into the police conduct (if an incorrectly performed search, then eventually an attack may occur). The police will also be able to switch between weapons, self-defense techniques, baton, pepper spray, and firearms. It has to capture clinical 
variation similarly to Issenberg et al.'s (2005) view on healthcare simulations. In the healthcare domain, Gaba (2004) points out that variations include conceptual understanding, technical skills, decisionmaking, teamwork and attitudes. In our case, it is conceptual understanding of the base tactical approach and local entry search. This can be supported by the simulator's ability to produce random variations of specific tasks (e.g., possible attacks, new risk areas), allowing repetition to support conceptual understanding.

c) The police should be able to get immediate feedback on their search. This means that risk areas have to be detected during the search so they understand what areas are secure or need to be investigated. Both how fast the police will recognize the risky areas and in what order will depend upon the situation. Feedback on their positioning in a room, how long they are standing at the same spot, etc. in relation to an evaluation of the risks is required. Further, the users should be able to go back and search an area if they realize they missed a space (cf. Issenberg et al.'s, 2005, view on repetitive practice for health care simulations).

d) The simulation must include different levels of difficulty (cf. Issenberg et al.'s, 2005, view on the importance of the range of difficulty level for clinical simulations in the healthcare domain.)

e) The search should be able to be performed with one and two police officers. Initially developed for a single patrol search, the ability to easily implement double patrol searches (a common work strategy in Sweden) needs to be considered.

f) The search should be recorded to enable reflection on the action a user performed in the simulation. This is important in order to enable for deep after-action debriefing (Crookall, 2010).

\section{The Environment Resource}

The environmental resource is either restricted to a computer in a computer lab or the student's personal computer. The simulation can be used both for individual as well as collaborative training. In both cases a specific task is identified to clarify the purpose of the simulation for the students, and the task is integrated into the curriculum and supports learning objectives (i.e., that simulation is not an extra-ordinary or extra-curricular activity but instead integrated into the core of the curriculum). The teacher or instructor can, depending on the purpose with CAST, adjust the environment and the curriculum integration.

If the simulation training is used in a computer lab a pedagogic steering of the training sessions can be accomplished which is not possible to the same extent when students install the application on their personal computers. Which alternative to choose depends on the purpose of the training and whether the students' interaction with the tool is mediated by other peers or an instructor. For example, to support reflective thinking by collaborative training using the 
simulation in a computer lab where students can sit together and collaborate or through a server solution where it is possible for two people to be "in the simulation" are both possible. The different uses give different possibilities for supporting the reflection-in-action as well as reflection-on-action. On the other hand, it can also be used for individual training, which has other effects on the reflective processes. In both cases there is a need for a clear task that supports the reflective processes in order to learn and understand local entry search tactics. The computer simulation's relation to the environment resource and the arrangement of it in relation to the aim of the simulation training is dependent on technological solutions. A more advanced technical solution that enables network cooperation contributes to other possibilities.

\section{Reflections on a Design Work in Progress}

Luckin's framework focuses our attention on key resources and filters in the learner's context and to the interaction between them. However, the ecology of resources model needs in the design of a computer simulator (the tool resource) to be informed by other theoretical perspectives or models to shed light on subject specific issues. In the design of CAST for learning complex police situations Schön's perspective on reflective thinking was applied to focus attention on reflective possibilities in the design process of a local entry clearance search. There are, however, areas in the described framework that might need to be informed by other theories and models to achieve a clearer subject specific design, such as learning engagement factors (game engagement) (Whitton, 2010), or the design dilemma perspective (Harteveld, Guimares, Mayer, \& Bidarra, 2009). The work performed so far is the development of a simulator prototype for single patrol search where students can, preferably in groups, act and discuss action strategies to enable reflectionin-action (peers can enhance subject specific reflections). Risk areas can be identified and marked and searches are recorded and can be used for reflection-on-action (after-action debriefing). The design process has been informed by the framework outlined here, and it is possible to add levels, scenarios, various feedback opportunities, etc., at a later date to achieve a fullscale solution with enough complexity.

Overall, the framework can help educators structure and objectify important aspects of a design for a computer simulator (e.g., tool), the simulation learning sessions, and its interplaying resources, and it supports the design of simulation learning. The described framework shows that different resources interplay with each other and for a fruitful learning experience with CAST all of them have to be considered. How, for example, can teachers/instructors adjust the ecology of resources model to support a group of learners? We have mentioned aspects as collaborative training but concerning the filter issue the interaction with the tool depends also on their background as gamers. In order to integrate a game-oriented CAST in teaching there is a need to identify their gaming experiences. This has to be done to establish the amount of training a student needs to manoeuver the simulation in order to transform the actual CAST to a learning experience. In the ongoing project a study has been made to identify how students with different gaming backgrounds manage the CAST to facilitate further curriculum integration. The design framework described, applying Luckin's framework to design of CAST informed by 
Schön, helps focus attention on issues that are important in the design process. However, there is a need for more research on different simulations and different scenarios informed by theoretical perspectives to enhance the knowledge about design for learning.

\section{References}

Chang, K-E., Chen, Y-L., Lin, H-Y., \& Sung, Y-T. (2008). Effects of learning support in simulation-based physics learning. Computers \& Education, 51(4), 1486-1498.

Crookall, D. (2010). Serious games, debriefing and simulation/gaming as a discipline. Simulation \& Gaming, 41 (6), 898-920.

Dalgarno, B., \& Lee, M. J. W. (2010). What are the learning affordances of 3D virtual environments. British Journal of Educational technology, 41(1), $10-32$.

de Freitas, S., \& Oliver, M. (2006). How can exploratory learning with games and simulations within the curriculum be most effectively evaluated? Computers \& Education, 46(3), 249-264.

Dewey, J. (1910). How we think. New York: Dover Publications.

Dieckmann, P. (Ed.). (2009). Using simulations for education, training and research. Lengerich: Pabst Science Publisher.

Gaba, D. M. (2004). The future vision of simulation in health care. Quality and Safety in Health Care, 13 (Supplement 1), 2-10.

Goodyear, P. (2005) Educational design and networked learning: Patterns, pattern languages and design practice. Australasian Journal of Educational Technology, 21(1), 82-101.

Häll, L-O., Söderström, T., Ahlqvist, J., \& Nilsson, T. (2011). Collaborative learning with screen-based simulation in health care education: An empirical study of collaborative patterns and proficiency development. Journal of Computer Assisted Learning, 27(5), 448-461.

Harteveld, C., Guimares, R., Mayer, I. S., \& Bidarra, R. (2009). Balancing play, meaning and reality: The design philosophy of LEVEE PATROLER. Simulation \& Gaming, 41(3), 316-340.

Holzinger, A., Kickmeier-Rust, M. D., Wassertheurer, S., \& Hessinger, M. (2009). Learning performance with interactive simulations in medical education: Lessons learned from results of leaning complex physiological models with the HAEMOdynamics SIMulator. Computers \& Education, 52(2), 292-301.

Issenberg, S. B., McGaghie, W. C., Petrusa, E. R. I., Lee, G. D., \& Scalese, R. J. (2005). Features and uses of high-fidelity medical simulations that lead to effective learning: A BEME systematic review. Medical Teacher, 27, $10-28$.

Luckin, R. (2008). The learner centric ecology of resources: A framework for using technology to scaffold learning. Computers \& Education, 50, 449-462.

Luckin, R. (2010). Re-designing learning contexts. Technology-rich, learner centred ecologies. London: Routledge.

Mawdesley, M., Long, G., Al-Jibouri, S., \& Scott, D. (2011). The enhancement of simulation based learning exercises through formalised 
reflection, focus group and group presentation. Computers \& Education, 56(1), 44-52.

Nehring, W. M., \& Lashley, F. R. (2009). Nursing simulation: A review of the past 40 years. Simulation \& Gaming, 40(4), 528-551.

Nilsson, T. A. (2007). Simulation supported training in oral radiology. Methods and impact in interpretative skill. Doctoral dissertation, Umeå University, Umeå.

Rieber, L. P., Tzeng, S-C., \& Tribble, K. (2004). Discovery learning, representation, and explanation within a computer-based simulation: Finding the right mix. Learning and instruction, 14(3), 307-323.

Schön, D. A. (1983). The reflective practitioner. How professionals think in action. New York: Basic Books.

Schön, D. A. (1987). Educating the reflective practitioner. San Francisco: Jossey-Bass.

Silén, C., Wirell, S., Kvist, J., Nylander, E., \& Smedby, Ö. (2008). Advanced $3 \mathrm{D}$ visualization in student-centred medical education. Medical Teacher, 30(5), 115-124.

Windschitl, M., \& Andre, T. (1998). Using computer simulations to enhance conceptual change: The roles of constructivist instruction and student epistemological beliefs. Journal of Research in Science Teaching, 35(2), $145-160$.

Whitton, N. (2010). Game engagement theory and adult learning. Simulation \& Gaming, 42(5), 596-609.

Vygotsky, L. S. (1978). Mind in society: The development of higher psychological processes. Cambridge: Harvard University Press. 